\title{
Del populismo al republicanismo
}

\author{
Daniel ABRALDES \\ Universidad Complutense de Madrid
}

Villacañas, José Luis: Populismo. Madrid, La Huerta Grande Editorial, 2015.

\begin{abstract}
Por mucho que el presente cultural y el tipo humano que forjan nuestras sociedades concedan más probabilidades de éxito al populismo, la opción republicana no ha perdido todas sus opciones. Este libro quisiera convencer a muchos populistas de que se pasen a esa otra opción.

José Luis Villacañas
\end{abstract}

El populismo sigue siendo, todavía hoy, el gran malentendido de nuestro tiempo. Los discursos sobre su naturaleza, sus recursos operativos o su propósito político, siguen estando acechados por una dispersión incapaz de constituir un campo de saber más o menos organizado. Por no saber, no sabemos ni siquiera cuál es su verdadero objeto, es decir, aquello que, para bien o para mal, bien pudiera merecer su nombre. Se habla de populismos de derecha y populismos de izquierda, de populismos nacionalistas e internacionalistas -o por lo menos supranacionales-, de populismos conservadores y, colmo de los pleonasmos, populismos "populares". Haciendo de la necesidad virtud, Laclau hizo de esta imprecisión fundamental el fundamento mismo de una comprensión ontológicamente retórica del populismo ${ }^{1}$. Para Laclau, el Dios ha muerto de Nietzsche ha llegado hasta el tuétano del ser y el tiempo postmetafísico de la retórica no tiene ya marcha atrás. El populismo sería la política de ese tiempo, o como dice el argentino: la ratio política tout court. El sociólogo italiano Marco D'Eramo, en cambio, toma esa imprecisión fundamental como indicio de algo distinto: ¿y si en la volatilidad del objeto hubiera que apreciar algo que concierne no al objeto sino a la propia práctica discursiva que lo constituye? Este cambio de perspectiva metodológica - un claro desplazamiento desde la ontología hacia la pragmática del discurso- es lo que le permitió afirmar que el tér-

${ }^{1}$ Cf. Laclau, La razón populista, Buenos Aires, FCE, 2005. 
mino "populista" no era ya una etiqueta científica -es decir, un descriptor conceptual, como había podido serlo aún en el siglo XIX o principios del XX-, sino más bien un hetero-definidor, es decir, un término con el cual el "extremocentrismo" de la política contemporánea descalifica o estigmatiza cualquier mínimo corrimiento de la agenda de recomposición oligárquica propia del neoliberalismo ${ }^{2}$. Es en medio de una polémica de este tipo -una polémica, pues, por la constitución misma del objeto teórico- donde tiene lugar la intervención ${ }^{3}$ de Villacañas.

El propio Villacañas parte, de hecho, de esta misma premisa: "Al comenzar a hablar de un fenómeno social o político se tiene que disponer ya previamente de un concepto ideal-tipo acreditado. Mi impresión es que, para el caso del populismo, no disponemos de tal concepto." (23, subrayado nuestro) Su tarea será por ello, en parte, producirlo, $y$, en parte, posicionarse críticamente frente a él, marcando las distancias que separan la propuesta populista de lo que él identifica como la agenda del republicanismo cívico. Hasta qué punto consigue producir un "concepto depurado" de populismo, es algo sobre lo que volveremos más adelante. Ahora interesa ver cuál es la estrategia desplegada a tales efectos.

La convicción acerca del carácter deficitario de la literatura científica disponible, impone la necesidad de desplegar un diálogo crítico con dicha literatura. Para poder organizar dicho diálogo, Villacañas comienza por diferenciar en ella al menos dos núcleos de teorización del populismo. El primero es el desarrollado desde una perspectiva "historiográfica" por autoras como Margaret Canovan o, más recientemente, Loris Zanatta ${ }^{4}$. El segundo es el desplegado desde un punto de vista más "sociológico" y "comunicacional" por un autor como Ernesto Laclau. El primero entiende al populismo como una ideología fundamentalmente reaccionaria, que se resiste a los avances impuestos por el proceso de modernización. El segundo lo piensa más bien como un fenómeno literalmente post-moderno, es decir, como un movimiento que surge no por oposición a la modernidad, sino, antes bien, como resultado de los procesos de descomposición social que ella arrastra consigo. Las preferencias teóricas de Villacañas resultan en este punto indisimulables:

La tesis genealógica central del libro de Zanatta dice con bastante claridad que el populismo es la forma en que tradiciones políticas católicas responden a la crisis de moder-

\footnotetext{
2 Cf. D’Eramo, “El populismo y la nueva oligarquía”, en New Left Review, Septiembre-Octubre 2013, pp. 7-40.

${ }^{3}$ El término "intervención" no es aquí ocioso. Lo empleamos con toda intención, porque al laborioso trabajo de esclarecimiento teórico, el libro de Villacañas añade la voluntad de elevar un juicio sobre las condiciones de posibilidad y desarrollo de una política populista en el seno de una realidad social como la que se verifica actualmente en España (caps. 14-5). Nos ocupamos de esta cuestión -su diagnosis del presente y su apuesta por el republicanismo cívico como propuesta política alternativa- hacia el final del presente escrito.

${ }^{4}$ Cf. Loris Zanatta, El populismo, Buenos Aires, Katz Editores, 2015.
} 
nización. Lo que provoca esa melancolía regenerativa de la comunidad ancestral -afirma Zanatta- es su nostalgia profunda del cuerpo místico católico. Así que Zanatta acaricia la teología política: el populismo es la forma secular de la política católica frente a la modernidad. En este sentido, concreta la tesis de Canovan, que habla del populismo como la política propia de pobladores rurales, que ante la presión del capital financiero, busca realizar valores tradicionales. En ambos casos, la conclusión invoca una teoría de la secularización todavía activa y no consumada. Ante las crisis endémicas de la modernidad, las sociedades católicas (o rurales) activan elementos que proceden de la melancolía de un universo religioso y sagrado. Lo político-católico produciría restos que están más allá de la potencia destructiva de la secularización y se activan en cada crisis de modernización. Así, las sociedades católicas serían específicamente refractarias a una secularización normalizada. Esa modernidad normalizada sería la perfectamente secularizada sociedad liberal. Al ignorar la novedad del populismo, Zanatta no puede ver que es un acontecimiento interno a la modernidad y una respuesta a sus dilemas y problemas estructurales. (32, subrayados míos)

La ventaja de la teoría posmarxista del populismo es, pues, que ella asume lo que una perspectiva "historiográfica" cargada de prejuicios ideológico-religiosos 5 parecía resuelta a ignorar. La interpretación posmarxista se mueve abiertamente en un plano inmanente al proceso de modernización, y no interpreta las crisis -que siempre fungen como precondición de la emergencia populista-como el producto de una resistencia arcaizante, sino más bien como el resultado de los "problemas generados por el propio éxito de la modernidad" y la manera en que esta, sometida a un proceso de aceleramiento extremo y descontrolado, acaba destruyendo "las tradiciones ancladas en el mundo de la vida" (37).

¿Quiere decir esto que Villacañas suscribe sin demasiados matices la interpretación posmarxista del populismo? Ni mucho menos. Lo que Villacañas convalida es el acierto teórico que constituye haber colocado la reflexión sobre el populismo en el contexto civilizatorio propio de la moderna sociedad de masas; por lo demás, su posición se mostrará más bien crítica. Se trata ante todo de precisar un concepto, y en esa labor de progresivo cincelamiento conceptual, la discusión de la posición posmarxista le será de sumo provecho, pues le permitirá ir desplegando poco

\footnotetext{
5 Esta idea acerca del carácter constitutivamente antimoderno del catolicismo no carece de precedentes. Carl Schmitt la explora a su manera en Catolicismo romano y forma política, pero, en general, la misma se apoya en una sesgada interpretación de la asociación weberiana entre protestantismo y modernización capitalista. Lo que es preciso entender es que sobrepasado el punto en el que la modernización necesita de una determinado ethos que la sostenga -o lo que es lo mismo: alcanzado el punto en el que el proceso de modernización se ha vuelto exclusivamente técnico y funciona inercialmente (y, en caso de requerir un ethos, necesitaría más bien de uno que la detenga o ralentice)-, esas asociaciones no pueden ser ya otra cosa que un prejuicio. Ahora bien, como sostiene acertadamente Villacañas, ese punto fue alcanzado hace ya no menos de un siglo: "desde Max Weber resulta evidente que las producciones modernas por excelencia, Estado y Capitalismo, ya han roto sus destinos convergentes.” (38)
} 
a poco lo que acaso podríamos denominar el problema de la subsidiariedad del populismo. Retomando la tesis acerca de "las raíces liberales" del populismo6, expuesta en otro momento en ocasión de una crítica al planteamiento teórico de Laclau, Villacañas consigue darle ahora un mayor nivel de concreción histórica y material. Esas "raíces" teóricas - e.g. la aceptación de la demanda como unidad mínima de análisis- no son sino el reflejo de una subsidiariedad estructural, de una dependencia orgánica que el populismo expresaría respecto de la agenda neoliberal. El punto fuerte de la tesis de Villacañas es, sin duda, la interfaz psicológica que este encuentra a la hora de articular esa subsidiariedad. Lo que el neoliberalismo arrasa como gobernanza económica es lo que el populismo recoge como el elemento psicológico de su política de masas7. Unos aparatos psíquicos colapsados por los inmisericordes dictados del Mercado se convierten de este modo en la materia prima de la política populista:

[...] el problema reside en que Freud va dejando de ser una autoridad en nuestro mundo. [...] Lo que está dejando sin uso a Freud no es la falta de evidencia de su terapia. Es más bien la formación de una sociedad cuyas condiciones materiales de existencia no pasan por el sueño de la singularización a través de herramientas culturales, ni por la novela familiar que constituía la existencia humana de la generación pasada, ni por la necesidad constitutiva del ideal del yo, algo cuyo solo planteamiento ya induce a la extrañeza.

En este sentido, nuestra sociedad promueve sujetos que no necesitan la instancia del yo ideal. [...] Se trata de la desaparición, en las nuevas condiciones técnicas del mundo de la vida, de la función del No, algo que afecta a los logros más bási-

\footnotetext{
${ }^{6}$ Cf. José Luis, Villacañas, “The Liberal Roots of Populism: A Critique of Laclau”, The New Centenial Review, vol. 10, no 2, pp. 151-82.

7 Sabemos que la teoría del populismo invoca a Freud y a su psicología de las masas para dotar de cobertura teórica la acción retórica del líder carismático (cf. Laclau, ob. cit., pp. 75-85). En un largo pasaje que merece ser considerado uno de los puntos álgidos de su argumentación (94-102), Villacañas demuestra hasta qué punto ese nombre es invocado vanamente: la normalización de la formación narcisista como tipo psicológico estándar, normalización que explicaría la omnipresencia de la razón populista como razón política tout court, no es una tesis freudiana como se pretende, sino, más bien, una interpretación deliberadamente reduccionista de su teoría: "Lo que extrae de aquí el populismo es que el aparato psíquico muestra la necesidad de liderazgo por razones estructurales del propio aparato psíquico. Pero esto no es así. El líder es probable en esta formación psíquica narcisista, no en cualquier otra. Alguien que tenga un yo ideal adecuado y distante, no asumirá bajo ningún concepto esta identificación, o lo hará bajo la forma del líder antiautoritario weberiano, sometido a responsabilidad. Pero disponer de un yo ideal que funcione como tal, que ofrezca instancias de autocrítica, ha sido la aspiración de singularización que atraviesa nuestra idea de libertad, que no tiene nada que ver con el gozo inmediato de bendecir nuestro yo real. Freud, por eso, reconoce que los grupos con líder son los más originarios y primitivos. Pero los seres humanos dotados de un yo ideal fuerte están en condiciones, dice Freud, de sustituir al líder por una idea abstracta." (99)
} 
cos que hicieron posible la humanización. Al desaparecer dicha función, es inviable la emergencia de instancias ideales de personalidad.

Aunque no podemos desplegar este tema apasionante, sí podemos decir lo siguiente: quien produzca pobreza cultural y falta de instancias ideales no debería quejarse del populismo. Al contrario: está produciendo las condiciones de posibilidad para que [el] populismo triunfe. Pero si nos preguntamos cuál es esa forma de vida en la que ningún deseo puede ser negado, no podremos sino responder que una sociedad que se entrega al mercado sin correcciones ni límites. Llamamos formación neoliberal a aquella sociedad que tiende a desarmarse de todos los criterios ajenos al mercado para su funcionamiento, aquella que solo produce libertad para el mercado. (103-5, subrayado nuestro)

Andando los años, la tesis de las "raíces" da lugar así a la tesis de la "alianza inesperada" (cap. 13), y la agenda política del "populismo" revela de este modo la verdadera naturaleza de ese límite o impotencia estructural que otros teóricos habían estado tentados de pensar en los términos heideggerianos de una diferencia ontológica imposible de reparar ${ }^{8}$. Lo que reduce la viabilidad de una política populista -esto, claro está, si aceptáramos que el concepto teórico de "populismo" desarrollado por Laclau refleja oportunamente la realidad de la política populista desplegada hoy en el mundo- no es pues la imposible plenitud expresiva del Seyn, sino, de un modo bastante más banal, el hecho de que la política populista va siempre a la zaga de una economía neoliberal que es, en definitiva, la que marca los límites materiales con que la gobernanza licua, o al menos restringe las posibilidades propositivas de todo "gobierno" 9 .

Esta "gobernanza" - término que no puede sino recordarnos la gubernamentalidad o gobernabilidad foucaultiana- parece ser pues el talón de Aquiles de la política populista: lo que la posibilita como formación reactiva, pero, al mismo tiempo,

\footnotetext{
8 Cf. Oliver Marchart, El pensamiento político posfundacional: la diferencia política en Nancy, Lefort, Badiou y Laclau, Buenos Aires, FCE, 2009.

9 A este respecto, cabría señalar aquí una importante contradicción en la posición desplegada por Villacañas. En el capítulo 11, Villacañas parece suscribir la posición según la cual "el populismo asume como principal objetivo el mantener las condiciones de posibilidad de las que brotó." (87, subrayados nuestros) Tenemos pues la imagen de una política populista que pudiendo progresar en la resolución de la catástrofe antropológica que la hace nacer, se acomoda en cambio en una retórica de la impotencia y resuelve obstinarse así en la prolongación indefinida de la circunstancia que que justifica su existencia. Esta posición no carece de antecedentes dentro de la teoría del populismo (en Laclau puede ser razonablemente inferida de su insistencia en la importancia de la construcción artificial del enemigo para el desarrollo de una identidad populista, pero además ha sido abiertamente sostenida por Ives Surel en su análisis del berlusconismo y se encuentra asimismo implícita en los desarrollos "heideggerianos" de la obra antes citada de Oliver Marchart), pero es preciso advertir hasta qué punto colisiona con esa otra tesis recién expuesta, tesis según la cual los límites de la política populista no son los límites de una impotencia deliberada, sino más bien los de una gobernanza difícil de desbaratar.
} 
lo que la limita y eventualmente la desbanca, merced a la acumulación de tensiones y contradicciones que produce una política a contramano. Si ello es así, y los procedimientos de toma de decisión económica están cada vez más automatizados y menos expuestos al influjo disuasorio de la responsabilidad social, entonces la propuesta del republicanismo cívico desglosada por Villacañas en el penúltimo capítulo (cap. 14) no parecería tener para ofrecer mucho más de lo que exhibe su desventurada competidora. Y en realidad, se diría que es el propio Villacañas quien se revela cada vez más consciente de ello al suavizar los términos de la confrontación. Si en un principio populismo y republicanismo aparecen como propuestas alternativas y hasta antagónicas, hacia el final de la obra vemos un progresivo acercamiento, conforme al cual "en realidad, podríamos decir que el populismo es el republicanismo mínimo de los tiempos póstumos, apocalípticos, desesperados, que Nietzsche anunciara con su gran política." (116-7) Es cierto que Villacañas jamás disolverá las fronteras por completo. Pero no lo es menos que tras unas cuantas intervenciones previas en las que la política populista era objeto de una abierta reconvención, el populismo aparece ahora como un objeto pasible de ser progresivamente republicanizado (aunque más no sea lenta y fatigosamente). Nuestra impresión es que Villacañas apostaría por ello, pero esa es ya una conclusión que quizá la obra no permita obtener sin una pizca de discrecionalidad de nuestra parte.

Daniel Abraldes

Universidad Complutense de Madrid abraldesd@gmail.com 